\title{
Revenue Management for Enhanced Profitability: An Introduction for Hotel Owners and Asset Managers
}

\author{
Chris Anderson and Sheryl Kimes
}

Most hotel managers are familiar with the term revenue management (RM), but RM for the hotel industry has evolved considerably from the original practice, which was developed two decades ago by American Airlines. As that company stated in its 1987 Annual Report, RM's goal is to maximize revenues by selling the right seat (or room, in the case of the hotel business) to the right customers and at the right time. ${ }^{1}$ While that definition states the essence of RM, as we discuss in this chapter, the hotel industry has refined the concepts of what is the right room, who is the right customer, and when is the right time.

At its most basic level, RM is about a hotel's ability to segment its consumers and price and control room inventory differently across these segments. - in essence practicing some form of price discrimination. In. many instances, RM used in the hotel industry has been shown to increase revenue by 2 to 5 percent. The high fixed cost and low variable cost typically associated with the hotel industry means that a large portion of this revenue increase flows directly to the bottom line. As an owner or manager, it is important that you understand what RM is, how it works, how it is typically organized, and how you measure its success. In addition, it is essential that you know the right questions to ask to help ensure that your property reaches its revenue potential. In this chapter, we will highlight the everchanging face of RM and what an owner needs to know about RM. The purpose of this chapter is to provide a broad overview of RM, enabling the reader to be knowledgeable enough to understand the underpinnings of today's RM systems.

\section{Revenue Management Actions}

Selling the right room to the right customers at the right time requires a revenue manager to forecast demand by market segment, understand the price sensitivity of these segments, and then adjust prices and control access to rooms. For the most part, hotel prices are market driven, and most hotels set rates relative to their competition. As a manager, you will have multiple rate classes or price points for each room type, with RM determining which of these rate classes should be available at any particular time. RM systems use existing reservations on hand $(\mathrm{ROH})$ to develop forecasts for future 
arrivals days. Booking or pace curves are a common way to present $\mathrm{ROH}$ as a function of days before arrival (DBA). Figure 14.1a displays a sample booking curve with the solid line representing typical $\mathrm{ROH}$ by DBA. The squares represent current $\mathrm{ROH}$ for a future arrival date, and the dashed line is the forecasted $\mathrm{ROH}$ over the next seven days prior to arrival. Hotels will generate multiple booking curves, one for each segment. Figure $14.1 \mathrm{~b}$ displays a sample set of booking curves one for regular rate the other for a discounted rate.

Depending on its size and reach, your hotel probably has numerous market segments. Typical ways to segment your customers are the channel they choose to book through, the number of nights they are staying, and the day of week $\mid C$ of their arrival. The more distinct segments you can identify and forecast, the more productive your RM system. The key is that the segments need to be $t$ distinct and separated by distinctive attributes or restrictions. Common sets of $y$. restrictions center around time of purchase, level of refundability, and affiliation with a particular business or organization. As shown in Figure 14.1b, the discount segment tends to book quite early, so you could set a rule that guests who want to qualify for this rate class would have to make their reservations 21 days or more prior to arrival. Other restrictions focus on exchangeability and transferability of the rooms as discounts often come at the expense of flexibility. Focusing on Figure $14.1 \mathrm{~b}$ helps us understand what an RM system is attempting to do. In that graph, the full-priced product doesn't have much demand prior to three or four days before arrival. If this were your property, you could be selling at the discounted rate up to four days before arrival and not worry much about full-price customers grabbing the discount rate. Then, at three days before arrival, you would need to be cautious with offering the discount rate, as y your fullprice customers are now in the market.

RM has often been motivated by a simple illustration of variable versus fixed pricing. Figure 14.2a shows a sample downward-sloping demand curve and a series of prices that might go with such a curve. The thing to look at here is that the areas trapped in rectangles on the left side of the graph, which represent revenue that your firm has captured, and the areas on the right, with the curved sides right next to the graph, represent forgone revenue. Hotels use a variety offences or restrictions so that they can sell a certain number of rooms at a discounted price while also being able to sell the remaining rooms at different prices (Table 14.1 summarizes some common rate restrictions). Your hotel or brand undoubtedly uses some of these. For example, in Figure $14.2 a$, the hotel sells 50 rooms at $\$ 175$, while simultaneously selling 50 rooms at $\$ 100$. The rate fences would have to restrict the 50 customers who were willing to pay the $\$ 175$ room rate from buying the room at the $\$ 100$ price, or (worse) $\$ 60$. The rate fences are not failsafe, and some of your customers who are willing to pay the higher rate will be happy 
to accept a lower price. Figure $14.2 \mathrm{~b}$ recasts the graph in $14.2 \mathrm{a}$ into the marketing view of variable pricing. Think of $14.2 \mathrm{a}$ as a price discrimination graph, and $14.2 \mathrm{~b}$ as a market segmentation approach, where each of the dashed lines presents a segment of the aggregated (total) market represented by the solid line. What you are attempting here is to set a revenue-maximizing price in each distinct market segment versus trying to discriminate across nonsegmented consumers. The point here is that unless your firm can effectively segment consumers (whether by fences or other mechanisms), you probably should not attempt to implement variable pricing.

\section{$\therefore$ its? $\quad$ Figure 14.1 Sample Booking Curves}

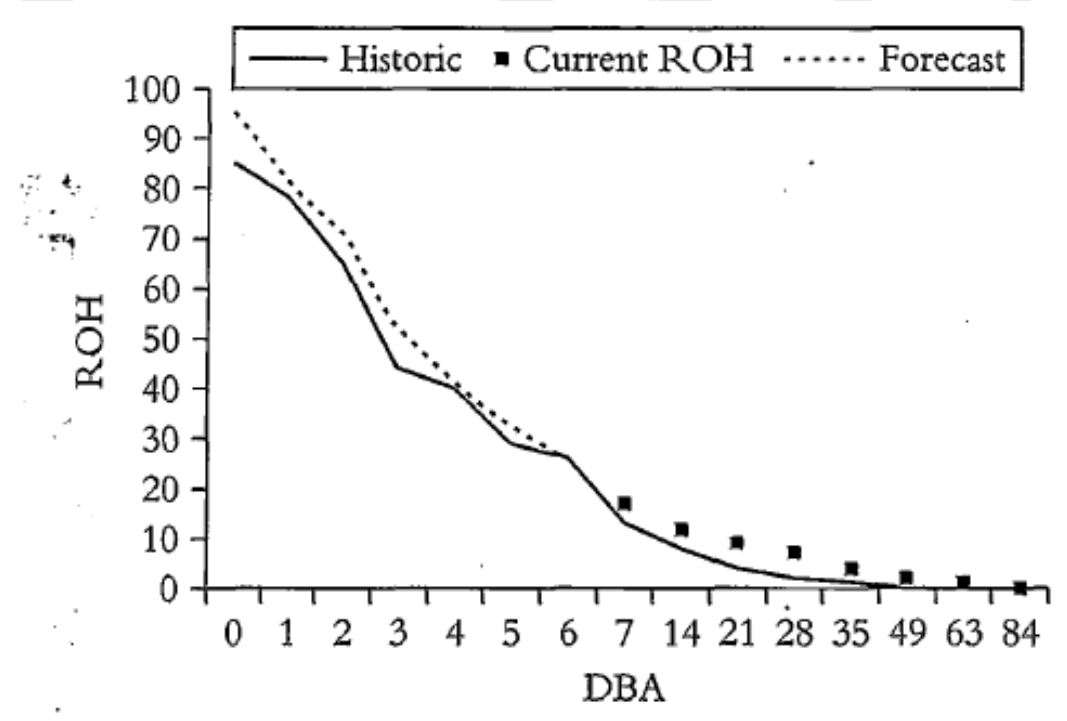

(a) Sample booking curve and forecast.

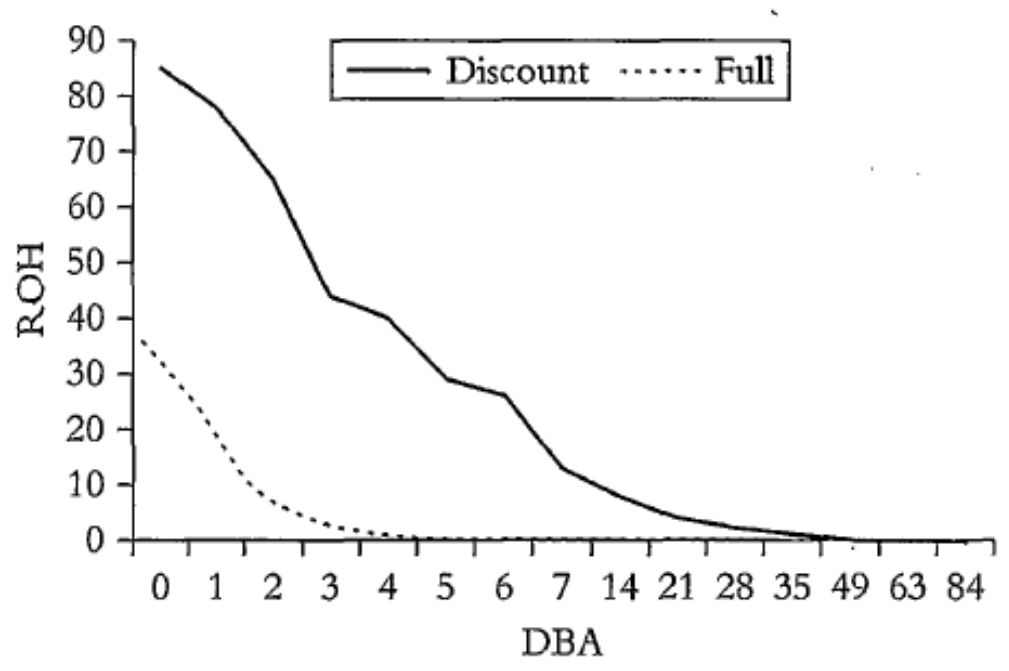

(b) Two-segment booking curve. 


\section{Figure 14.2}

\section{Variable Pricing and Segmentation}

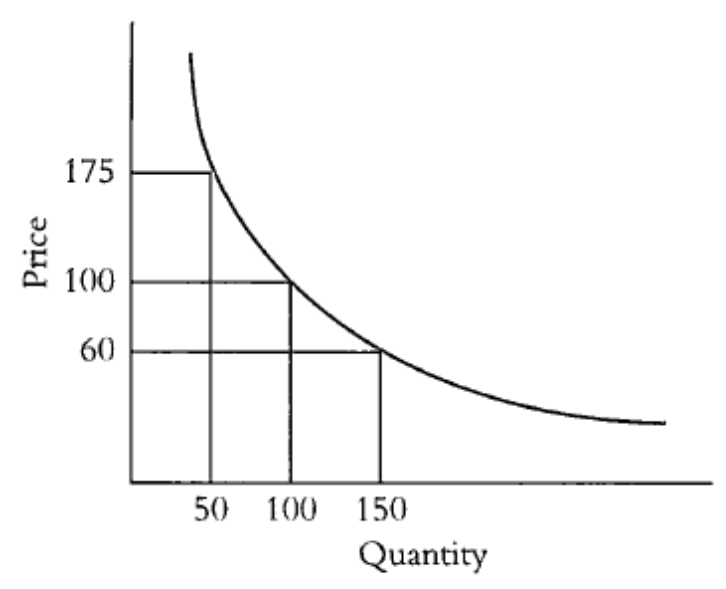

(a) Variable Pricing-price discrimination.

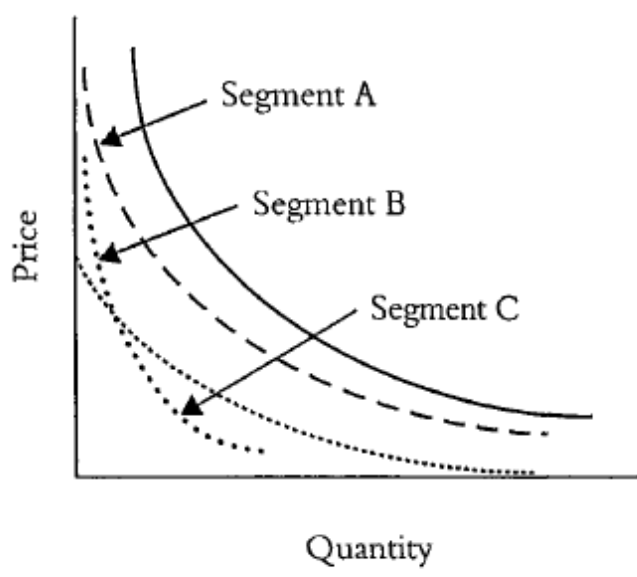

(b) Variable Pricing-market segmentation.

Variable Pricing and Dynamic Pricing

We've been talking about variable pricing, but let's compare that with a different way to set prices-dynamic pricing. As we just explained, variable pricing involves setting multiple price points for distinct market segments. The key facet is that each price could potentially be offered simultaneously. In contrast, dynamic pricing involves changing prices over time in response to demand uncertainty (usually, you decrease your price in an attempt to stimulate demand, or increase prices in response to strong demand). Be careful with rate reductions because you could lower your rates (and dilute your ADR) without improving occupancy. When contemplating a rate change, you need to first assess the demand response that would be required to make the contribution from the price change positive. For example, consider a hotel that is contemplating decreasing its room rate from $\$ 100$ to $\$ 90$. Say that the hotel would have sold 90 rooms at $\$ 100$ (for revenue of $\$ 9,000$ ). To break even at the $\$ 90$ room rate, the hotel would need to sell at least 100 rooms. If we further assume that the hotel has a variable cost of $\$ 20$ per room, the contribution at the $\$ 100$ rate would be $(\$ 100-\$ 20) \times 90$ rooms $=\$ 7,200$. To break even at the $\$ 90$ rate, taking contribution into account, the hotel would need to be able to sell 103 rooms (contributing $\$ 70$ each) to hit $\$ 7,200$. 
Table 14.1

Common Rate Fences

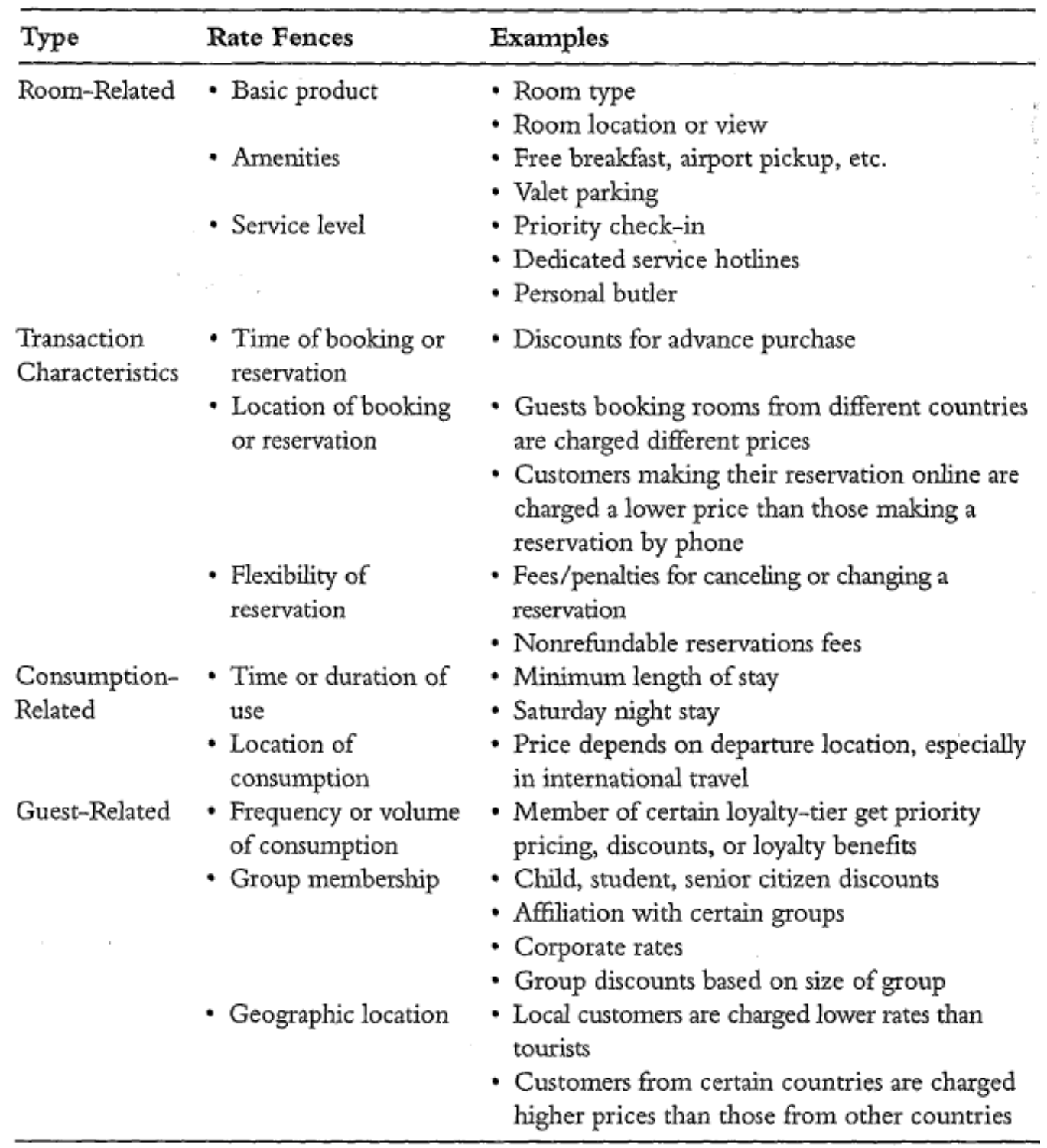

We suggest being careful with rate reductions for the following reason: Not all segments respond to rate changes with more demand; that is, they are not price elastic. As you consider your breakeven analysis, you need to take into account two possible actions, depending on whether a particular market segment is price elastic (and responds to rate changes) or price inelastic. You can:

- $\quad$ Decrease prices (by either doing it alone or following a competitor's rate reduction) in price sensitive (elastic) segments, or

- $\quad$ Raise prices (or follow a competitor's price increase) in non-price sensitive (inelastic) segments. 
The key term here is segments, which are the groups of guests who have certain booking attributes in common. Using the rate fences, you can target price changes at specific market segments, as only targeted price changes will generate enough incremental demand to compensate for rate dilution, which occurs when you give a relatively low rate to guests who would have willingly paid more.

Hotels need to differentiate between variable and dynamic pricing. Restrictions and rate fences can be effective at setting variable prices but are less effective at controlling availability.

While firms can use time-based segmentation, they generally use some form of fencing to segment consumers. Your hotel can segment consumers (charge different prices) across room and bed type. Looking again at Table 14.1, you can see that other common types of rate fence include transaction characteristics, consumption characteristics, and customer characteristics.

Because most hotel rates are posted online, customers can compare rates both for different hotels and for various distribution channels. Your hotel undoubtedly maintains price parity on various distribution channels. So your strategy here is to have a series of private rates. We discuss these private rates in more detail in Chapter 26, which addresses strategies for dealing with difficult markets. Private (or opaque) discounts allow you to offer special prices to price-sensitive customers while maintaining higher prices on regular posted price channels. Many hotels offer their private discounts on opaque online travel agents, like Priceline's "Name Your Own Price" channel ${ }^{2}$ or on Hotwire.com. ${ }^{3}$ Both Hotwire and Priceline hide the name of the property until after the purchase, allowing the service provider to reach price-sensitive customers (who are not brand loyal), while simultaneously maintaining their higher price for brand-loyal customers. Another method of offering private discounts is to package your room with other hotel services (e.g., spa, food, and beverages). The package price is lower than the sum of all the individual prices, but no one can determine how you have apportioned them. Finally, today's online advertising world offers numerous ways to market to individual customers whether via your customer relationship marketing (CRM) system with e-mail offers (where you are using your database of past customers and their travel patterns to create specific offers) or through search engine marketing (e.g., using Google, Yahoo!, or Bing), where you can pay for specific exposure of your ads with links to special reduced prices. Again, we discuss these tactics in greater detail in Chapter 26. With dynamic pricing you run the risk of turning your hotel room into a commodity that is simply purchased on price, as has largely occurred with airline seats, where customers switch airlines to save only a few dollars.

In both recent economic downturns, we have seen many hotels using online travel agents (OTAs) as a means of reaching price-sensitive consumers. This has potential benefits, in addition to the risks. A recent study by Continental Airlines illustrates that while average fares have dropped as 
consumers moved online to shop and purchase travel, consumers have responded to the airlines' rate fences by choosing to purchase in off-peak periods to obtain lower prices, thereby smoothing out demand. ${ }^{4}$ One could conclude that prices are not decreasing, but rather that these online channels are reaching price-sensitive consumers who may not have otherwise purchased a flight. In a related experimental study, chapter coauthor Anderson showed that not only do OTAs generate incremental reservations at the OTA itself, but they also significantly increase reservation volume at non-OTA channels (such as the hotel's own Web site, call center, or traditional travel agent). ${ }^{5}$ That study found an approximate lift of 20 percent in reservations was obtained by listing on OTAs like Expedia, Orbitz, or Travelocity. Together, these two studies illustrate the strategic role of OTAs in generating reservations. Again, a note of caution: Use these OTAs strategically and rely on these channels only at times when price-sensitive customers are shopping. More to the point, you need to make sure that you remove these deals when your full-price segments are starting to book. Think of the OTA as a marketing expense, marketing toward price-sensitive consumers. So you use the OTA if you think it's the most efficient use of your marketing dollars.

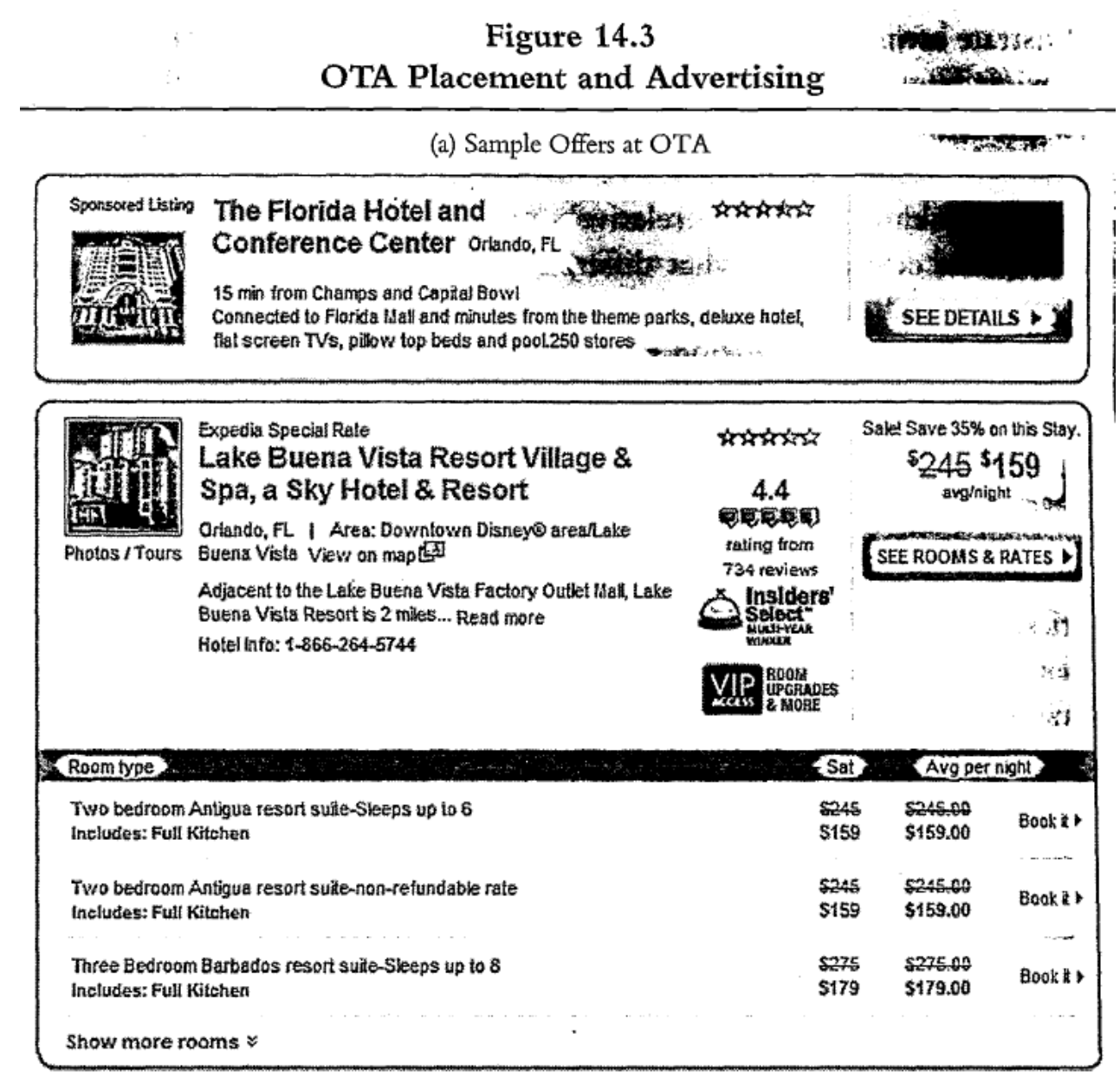


Like the search engines, OTAs also allow you to purchase Web page positions and advertising. Figure 14.3 shows two types of sample offers at an OTA. The first listing is a sponsored listing where the property has paid to be prominently displayed at the top of the hotel list. You can also use strategies that involve "deals" for the consumer (often as part of engaging the OTAs' services). The listing just below the sponsored listing uses strikethrough pricing (regular price is crossed out with discounted price listed) to demonstrate savings and to create a sense of urgency in an effort to increase conversion rates. Figure 14.4 shows a sample banner ad typically displayed | down the left-hand side of the OTA listing. Most OTAs also offer Deal or Special Offer sections where hotels can provide special offers and packages. Generally speaking, OTAs are relatively consistent in the products and services they offer consumers; what differentiates each is their ability to market to consumers and drive traffic to the specific OTA. Figure 14.5 .summarizes average monthly visitors during the $2008-2009$ recession to the four largest North American OTAs.

Most North American OTAs operate on the merchant model. That is, they are the merchant of record in which the OTA sells an agreed-upon number of rooms at an agreed-upon price, which represents the amount you will receive after the OTA marks the price up and sells the rooms. Outside of North America, many OTAs operate on a retail model in which they receive a com- mission for each sale. Some of these retail OTAs allow hotels to pay higher commissions in exchange for prominent display at the top of their "Web pages.

(b) Banner ad

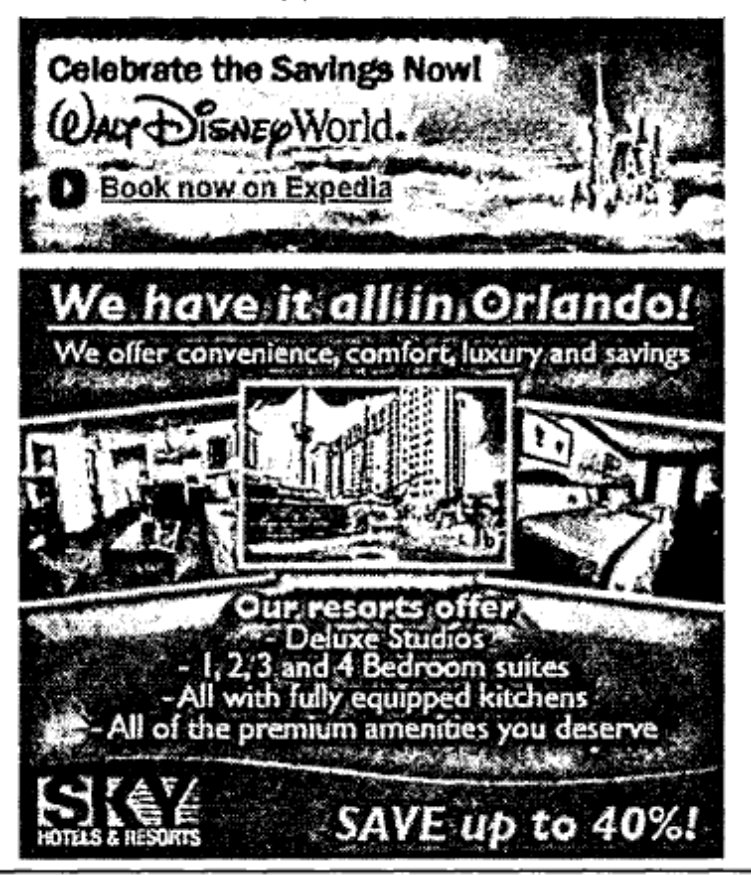


Figure 14.4

Sample Menu Bar Showing Deals at Expedia.com

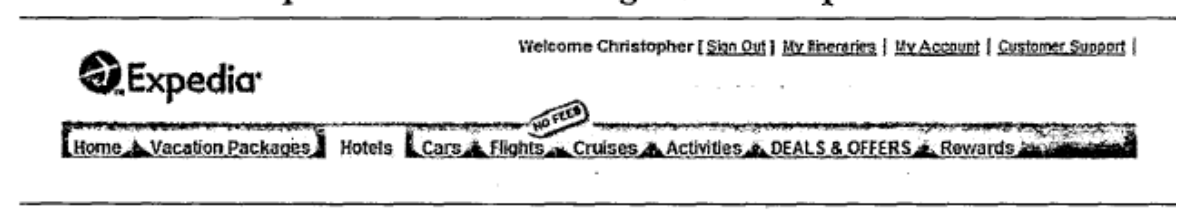

Figure 14.5

Unique Monthly Visitors (Millions)

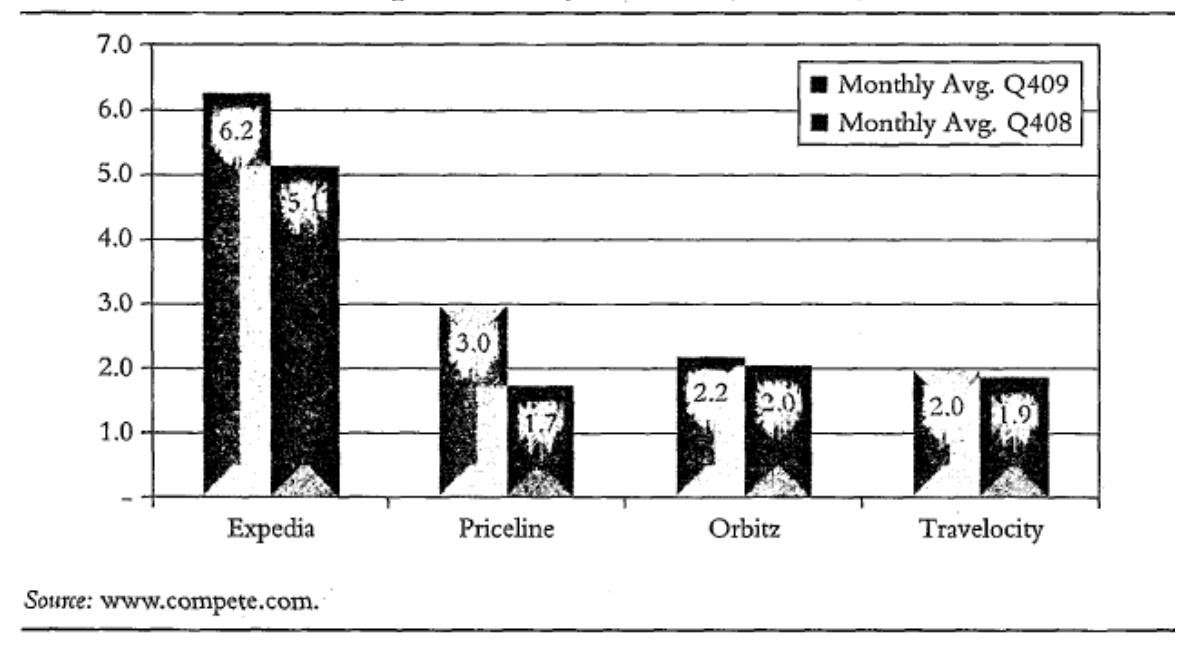

Although we go into greater detail in Chapter 26, we need to mention search engine marketing (SEM) and search engine optimization (SEO) in connection with this discussion. You can use the search engines as marketing vehicles, especially since many consumers start with a search engine to research travel opportunities before they go on to other travel sites (e.g.,' OTAs). Ensuring that your hotel has prime placement on the search engine will undoubtedly drive more demand further down the search funnel. Figure 14.6, a display of a Google search on hotels in red wing, illustrates the SEM and SEO principles. This search stems from a project with the St. James Hotel in Red Wing, Minnesota. ${ }^{6}$ As you can see, the hotel's URL (www.st-james-hotel.com) is high on the list. They have used SEM to purchase a pay-per-click (PPC) ad, which is fifth down the list of ads on the right-hand side. They may have also optimized their Web site with appropriate search terms so that when someone types in "hotels in red wing," their property comes up near the top of the (unpaid) list. When looking at this first-page result, we see both direct competitors to the St. James being listed (e.g., American Inn), as well as the OTAs, which are also using PPC. SEM will increasingly become an important aspect of all RM activities at a property, as it provides as easy to implement a targeted approach to generating demand. Again, see Chapter 26 for tactics that will benefit your hotel in using this strategy. 
Figure 14.6

SEO and SEM at the St. James Hotel

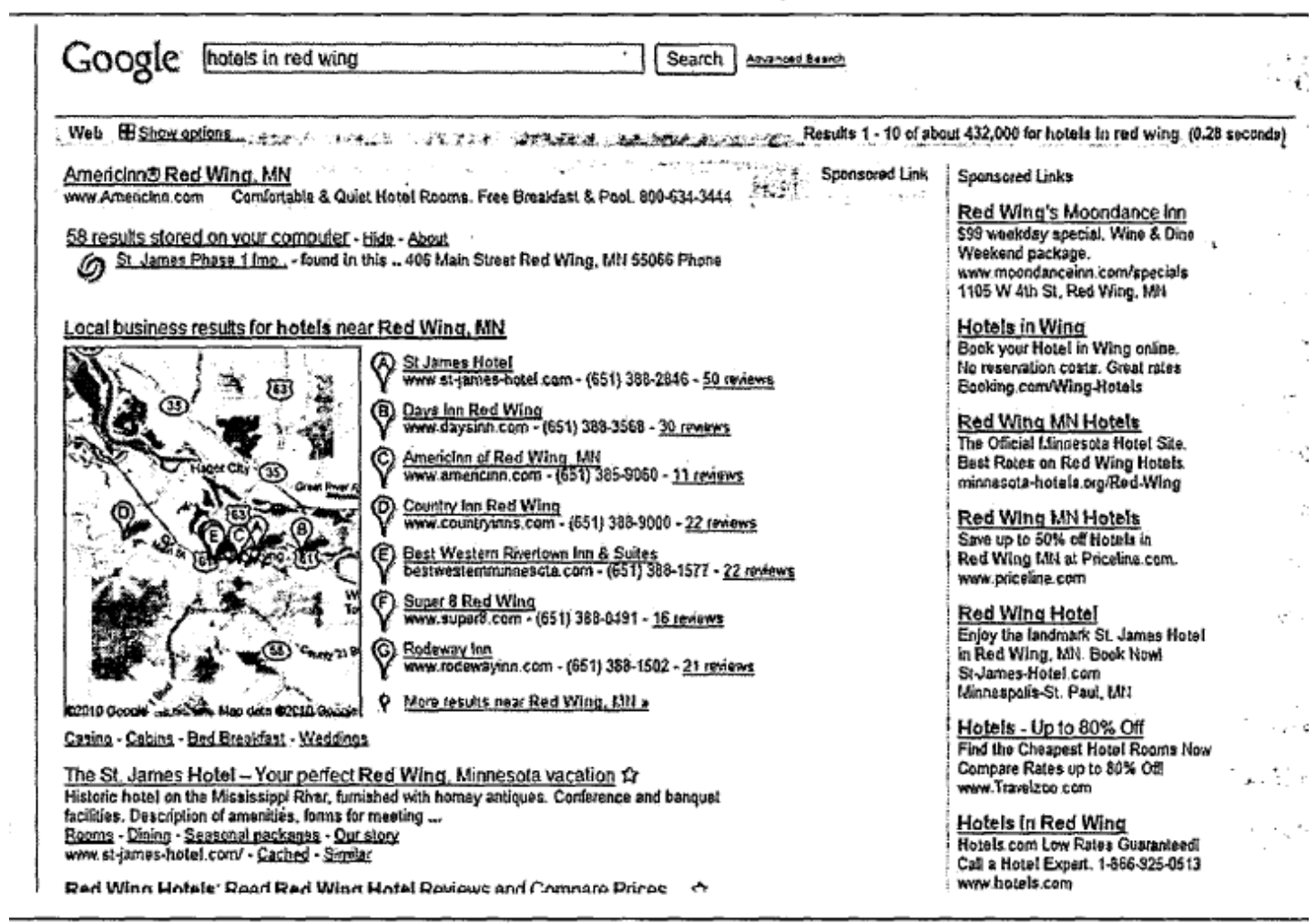

Performance Measurement

To determine which of the many price discrimination tactics are working best for you, you'll probably want to use the typical hotel financial ratios, especially revenue per available room (RevPAR), although some properties also keep track of gross operating profit (GOP). The typical RevPAR calculation is to multiply the occupancy percentage by your ADR, but you can also divide your total rooms revenue by the number of rooms available. RevPAR has a direct effect on the capitalization (cap) rate, cash flow, and net operating income. A small percentage increase in RevPAR can yield a substantial percentage gain in cap rate. Further details on capitalization rates are found in Chapter 18 by John Corgel

Most likely, you will compare your hotel's performance with that of its competitive set. Because of the hotel industry's cost structure, the focus of RM is typically on guest room sales and particularly on room revenue. RevPAR f clearly matters, but you probably want to look at how your hotel is doing compared to the market. After all, a 10 percent increase in RevPAR during a strong economy may not be particularly good if the market is up by 20 percent. Most North American hotels and many hotels in other parts of the world subscribe to services that compare their performance with that of their 
competitive set. The most commonly used source for this information is Smith Travel Research (STR) but other organizations provide similar data. Let's take a look at how to work with STR data (often referred to as STAR reports).

Depending on the subscription level, hotels share with STR their performance data (occupancy and ADR) each month or each day. In that report, you would also specify the composition of your competitive set (at least three or four other similar hotels, usually located close by). You could have several comp sets-say, one comp set that consists of nearby hotels and another comp set that looks at similar hotels that may be located a bit farther away. Owners need to watch to make sure that the comp set is appropriately chosen, because a poorly chosen comp set can misrepresent a hotel's relative performance.

STR uses submitted data to develop occupancy, ADR, and RevPAR information for both the individual hotel and for the competitive set. Data for the competitive set are aggregated because of government regulations, so that you do not directly know who reported which results.

STR then develops indices for occupancy, ADR, and RevPAR that compare your individual hotel's performance with that of its competitive set. The indices are calculated by dividing the hotel's performance by that of its competitive set. Indices above 100 indicate that the hotel is outperforming its competitive set; those below 100 mean that the hotel is underperforming its competitive set. For example, if your hotel has occupancy of 77 percent and its competitive set has occupancy of 70 percent, you have an occupancy index of 110 (77/70).

The indices conveniently show how well a hotel is performing regardless the economic situation. The index that commands the most attention is the RevPAR index. If your hotel does not have a RevPAR index of above 100, you should ask why and investigate ways in which to improve it. Obviously, to have a RevPAR index above 100, one of the occupancy and ADR indices must also be above 100 (or ideally both).

During a down market, some hotels and owners may try to raise RevPAR by dropping rate in an attempt to raise occupancy. While such a tactic is tempting, you need to be careful that the ADR index does not fall below that of its competitive set. Research has shown that hotels that have an ADR index of less than 100 have a lower RevPAR index than hotels that have a higher ADR index. Various chapters in this book touch on this research, but the most complete discussion is in the next chapter, on management strategy. The short of it is that dropping rates has implications for the long-term success of the hotel. $^{7}$ 
The important thing to remember with ADR is that it is an average of multiple rates. Think of revenue coming into the hotel as a pipe with multiple inlets. The inlets represent different market segments and distribution channels with different demand levels and price sensitivities. By adjusting the flow of the different demand inputs, you can better manage revenue flow. For example, during slow periods, you might want to increase the flow of business from certain market segments and distribution channels, but you may choose to restrict this demand during busier time. Your RM system will indicate how and when to adjust the flow levels of the different demand sources.

\section{Organization of the RM Function}

If your hotel has not integrated revenue management as a total strategy throughout your hotel, we urge you to start now. Hotel RM began as a function of the local property's reservations department-focused only on room sales. That's still important, but over the past 15 years, RM has taken on a more strategic and marketing function. RM is typically located either in the sales and marketing department or is sometimes placed in a separate department that reports directly to the hotel's general manager. Given the importance of RM in generating a steady cash flow for the hotel, we suggest that the revenue manager should be part of your hotel's executive team.

Brands have taken note of the importance of revenue management, and a number of chains have adopted a relatively centralized approach in which RM is handled at the city or regional level. With this approach, one revenue manager might have responsibility for 10 to 20 hotels. An alternative approach often seen at more moderately priced hotel chains is to completely centralize RM and to have all revenue managed from the corporate office.

If you own a hotel that is part of a chain, you may need to decide whether you will opt in to that chains RM system. In most cases, this is probably a good idea, but before making the decision, be sure to ask to see the performance data of their system.

\section{RM for Other Parts of the Hotel}

Revenue management can be applied to numerous revenue streams in your hotel including function space, ${ }^{8}$ restaurants, ${ }^{9}$ spas, ${ }^{10}$ and golf courses. ${ }^{11}$ Any part of the hotel that sells space (whether it be a guest room, meeting space, or a restaurant seat) for a given length of time for a variety of prices has the opportunity to apply RM principles. Essentially, RM can be applied to maximize the revenue per available square foot of the entire hotel. 


\section{Key Questions to Ask}

Often, one of the major hurdles in understanding or implementing RM is not knowing the right questions to ask of the stakeholders involved in using the system as well as those looking to you to use their system. Following are some key questions you might use to gather further insight into what your RM system (or your potential system) is doing and how well it is doing it.

1. What sort of RM system are you using?

The answers to this will vary from "We're using the corporate system" to "We're using a manual system." Here's how to respond to the three most common responses:

"We're using the corporate system." This is probably good since most major chains have relatively strong RM systems. Key questions to follow up with include:

- Who is responsible for using the system?

- What sort of training has the person gone through?

- How are the results from the system used to make decisions?

- $\quad$ "We're using a purchased system." Again, this is probably good since there are a number of good commercial RM systems, but some are better than others. Key questions to follow up with include:

- What other hotels use this system? What sort of success have they had?

- Why did you choose this system?

- Who is responsible for using the system?

- What sort of training has the person gone through?

- How are the results from the system used to make decisions?

"We're using a manual system." This means either that they are not doing much of anything or that they're using a series of Excel spreadsheets to make decisions. This approach can work, but its success is largely dependent on the caliber of the person who is responsible for making the RM decisions. Key follow-up questions include:

- Why are you using this approach rather than using a purchased system?

- Who is responsible for using the system?

- What sort of training has the person gone through?

- How are the results from the system used to make decisions? 
2. How are you using online travel agents? Are you a preferred partner, merchant model, or are you just using the retail model?

3. Are you using any opaque distribution channels such as Priceline.com? If so, how do you use it and what results have you had? If not, why not?

4. How do you make pricing decisions? How frequently do you change rates? How do you decide if a price move is required? How do you evaluate price changes (i.e., what sort of after the fact performance measurements are you making)?

5. How frequently do you have yield meetings? Who attends? Who is in charge? What sorts of things are discussed? What sorts of reports are generated?

6. How do you use STR reports and other competitive data to make decisions? How frequently do you "shop" the competition? Do you shop manually or do you use a service? If you use a service, which one do you use?

7. Tell me more about the revenue manager. What department is he/she located in? What sort of background does the person have? What sort of training does the person have?

8. Where do your reservations come from? What percentage come from the hotel's Web site, OTAs, call centers etc.?

9. What did you do to survive the last recession? What worked? What didn't work?

\section{Summary}

Revenue management in the hotel industry continues to evolve. The recession of 2008-2009 particularly caused hotels to reevaluate and to adjust to situations of surplus capacity-instead of surplus demand. The strategic importance of RM became particularly apparent when demand plunged. Hotels needed to carefully consider their tactics for attracting price-sensitive demand. As we see it, RM is evolving into demand management, a practice that is integrated with sales and marketing. RM will be an exciting place over the next few years as firms further integrate their online efforts as well as embrace mobile technology. Today, it is critical for ownership to be cognizant of how their properly is embracing the opportunities created by RM. It will be the firms with targeted marketing and discounting programs that are integrated with RM that lead rates up as the economy improves.

\footnotetext{
${ }^{1}$ American Airlines, "The Art of Managing Yield," Annual Report (1987): 22-25.

${ }^{2}$ C. K. Anderson, "Setting Prices on Priceline," Interfaces 39(4) (2009): 307-315.

${ }^{3}$ C. K. Anderson and X. Xie, "A Choice-Based Dynamic Programming Approach for Setting Opaque Prices." Cornell University, School of Hotel Administration, Working Paper, 2009.
} 
${ }^{4}$ W. G. Brunger, "The Impact of the Internet on Airline Fares: The Internet Price Effect," Journal of Revenue Management and Pricing 9(2) (2009): 66-93.

${ }^{5}$ C. K. Anderson, "The Billboard Effect: Online Travel Agent Impact on Non-OTA Reservation Volume," Cornell Center for Hospitality Research Report 9(16) (2009).

${ }^{6}$ C. K. Anderson, G. Bodenlos, V. Bogert, D. Gordon, and C Hearne, "SEO/ SEM Best Practices: The St. James Hotel," Cornell University School of Hotel Administration, Working Paper, 2010.

${ }^{7}$ C. Enz, L. Canina, and M. Lomanno, "Competitive Pricing Decisions in Uncertain Times," Cornell Hospitality Quarterly 50(3) (2009): 325-341.

${ }^{8}$ S. E. Kimes and K. A. McGuire, "Function Space Revenue Management: A Case Study from Singapore," Cornell Hotel and Restaurant Administration Quarterly 42(6) (2001): 33-46; and S. Hormby, J. Morrison, P. Dave, M. Meyers, and T Tenca, "Marriott International Increases Revenue by Implementing a Group Pricing Optimizer," Interfaces 40(1) (2010): 47-57.

${ }^{9}$ S. E. Kimes, R. B. Chase, S. Choi, E. N. Ngonzi, and P. Y. Lee, "Restaurant Revenue Management," Cornell Hotel and Restaurant Administration Quarterly 40((1998): 40-45; D. Bertsimas and R. Shioda, "Restaurant Revenue Management, Operations Research 51(3) (2003): 472-486.

${ }^{10}$ S. E. Kimes and S. Singh, "Spa Revenue Management," Cornell Hospitality Quarterly 50(1) (2009): 82-95.

${ }^{11}$ S. E. Kimes,. "Revenue Management on the Links: Applying Yield Management to the Golf-Course Industry," Cornell Hotel and Restaurant Administration Quarterly 41(1) (2000): 120-127. 